\title{
Effect of the Aperture Ratio on the Impedance Bandwidth of an Aperture Coupled Microstrip Antenna
}

\author{
Jae-Hyun KIM, Boo-Gyoun KIM \\ School of Electronic Engineering, Soongsil University, Dongjak-gu, 06978 Seoul, Korea \\ join3@soongsil.ac.kr, bgkim0325@ssu.ac.kr \\ Submitted December 8, 2017 / Accepted February 5, 2018
}

\begin{abstract}
The effect of the aperture ratio on the impedance bandwidth of an aperture coupled microstrip antenna (ACMA) is investigated according to the coupling strength from a microstrip feed line to a patch. Since the coupling strength between a feed line and a patch of an ACMA with a high permittivity $\left(\varepsilon_{r}=10\right)$ feed substrate is small, the impedance bandwidth of the ACMA increases as the aperture ratio increases beyond 0.1. As the feed substrate thickness increases, the aperture ratio for the maximum impedance bandwidth increases and the ratio of the maximum impedance bandwidth to the impedance bandwidth obtained at the aperture ratio of 0.1 increases. Since the coupling strength between a feed line and a patch of an ACMA with a low permittivity $\left(\varepsilon_{r}=2.2\right)$ feed substrate is large, the maximum impedance bandwidth of the ACMA is approximately the same as the impedance bandwidth obtained at the aperture ratio of 0.1 .
\end{abstract}

\section{Keywords}

Aperture coupled antenna, bandwidth enhancement, aperture width, aperture length, feed substrate, MMIC

\section{Introduction}

Microstrip patch antennas are currently being used for many applications because they have many advantageous features such as low profile, light weight, conformability, and low fabrication cost. In addition, they are suitable for integration with monolithic microwave integrated circuits (MMICs) [1], [2]. An aperture coupled microstrip antenna (ACMA) can use two different dielectric substrates separated by a common ground plane. This configuration of an ACMA is particularly useful compared to other feeding methods when integrating an antenna with an MMIC [3]. However, the inherent narrow impedance bandwidth of an ACMA is a major barrier to implementing these antennas in many applications.

Many works have been performed to enhance the impedance bandwidth of ACMAs and their variations [1-4]. Among the techniques used to enhance the bandwidth of ACMAs, two techniques are widely utilized: the stacked patch, in which a parasitic element is placed above a lower patch [5-6] and utilization of the mutual resonance produced by the interaction of the aperture with the patch [5]. In most studies, ACMAs and the aperture stacked patch (ASP) antennas with low permittivity $\left(\varepsilon_{\mathrm{r}}<2.5\right)$ feed substrates have been investigated to obtain wide impedance bandwidth [5-7]. MMICs have been manufactured using high permittivity $\left(\varepsilon_{\mathrm{r}}>10\right)$ substrates such as $\mathrm{Si}$ or GaAs. Thus, antennas suitable for integration with MMICs should be designed on a high permittivity feed substrate. The impedance bandwidth of an ACMA with a high permittivity feed substrate is usually smaller than that of an ACMA with a low permittivity feed substrate [3], [8].

Many studies have been performed to investigate the effects of aperture length and of the permittivity and thickness of the antenna and feed substrates on the impedance bandwidth of an ACMA [2], [9]. However, to the best of the authors' knowledge, the effect of the aperture ratio on the impedance bandwidth of an ACMA according to the coupling strength from a feed line to a patch has not yet been investigated. The aperture ratio is defined as the ratio of aperture width to length. However, Pozar presented the design guideline of the aperture ratio of an ACMA to be typically $0.1[10]$.

Liu et al. presented the turns ratio $n_{\mathrm{f}}$ modeling the coupling between the feed line and the aperture of an ACMA as a function of aperture length and feed substrate thickness. Also, they presented the turns ratio $n_{\mathrm{p}}$ modeling the coupling between the aperture and the patch as a function of aperture length and patch width. They obtained excellent agreement between the simulation results using the equivalent circuit with $n_{\mathrm{f}}$ and $n_{\mathrm{p}}$ and experiment results for the frequency response of the return loss of an ACMA [11].

In this paper, we investigated the effect of the aperture ratio on the impedance bandwidth of an ACMA according to the coupling strength from a feed line to a patch. In order to minimize the number of parameters affecting the impedance bandwidth, the antenna substrate used in this study is a $3.2 \mathrm{~mm}$-thick Taconic TLY-5 substrate $\left(\varepsilon_{\mathrm{r}}=\right.$ $2.2, \tan \delta=0.0009)$. Two types of substrates having different permittivities were used as the feed substrate. One feed substrate selected in this study is the Taconic CER-10 
substrate $\left(\varepsilon_{\mathrm{r}}=10, \tan \delta=0.0035\right)$ to simulate the high permittivity materials typically used for MMIC fabrication. The other feed substrate is the Taconic TLY-5 substrate. A wide impedance bandwidth was obtained using the mutual resonance produced by the interaction between the aperture and the patch.

Since the aperture length of an ACMA with a low permittivity $\left(\varepsilon_{\mathrm{r}}=2.2\right)$ feed substrate is longer than that with a high permittivity $\left(\varepsilon_{\mathrm{r}}=10\right)$ feed substrate, the coupling strength from a feed line to a patch of an ACMA with the low permittivity feed substrate is larger than that with the high permittivity feed substrate. The ACMAs with the low permittivity feed substrate with three different thicknesses used in this study have the maximum impedance bandwidth when the aperture ratio is around 0.1 . However, the impedance bandwidths of ACMAs with the high permittivity feed substrate with three different thicknesses increase as the aperture ratio increases beyond 0.1. High Frequency Structure Simulator (HFSS) was used for simulations in this work.

This paper is organized as follows. Section 2 presents the design parameters of three ACMAs with the low permittivity feed substrate with three different thicknesses as well as those with the high permittivity feed substrate with three different thicknesses required to obtain the maximum impedance bandwidth when the aperture ratio has a typical value of 0.1 . The coupling strength from a feed line to a patch is presented for each ACMA. The effect of the aperture ratio on the impedance bandwidth of an ACMA is investigated according to the coupling strength from a feed line to a patch. In Sec. 3, the simulated and measured results of the impedance bandwidth and radiation characteristics of the ACMAs with the high permittivity feed substrate are presented for various aperture ratios. Finally, Section 4 concludes the paper.

\section{Effect of the Aperture Ratio on the Impedance Bandwidth of an ACMA according to the Coupling Strength from a Feed Line to a Patch}

Figure 1 shows a schematic diagram of an ACMA. The antenna consists of two substrates separated by a common ground plane. A rectangular aperture with the dimensions of $L_{\text {ap }} \times W_{\text {ap }}$ is etched on the ground plane. The dimensions of the patch are $L_{\mathrm{p}} \times W_{\mathrm{p}}$. The dielectric constant and thickness of the feed (antenna) substrate are denoted as $\varepsilon_{\mathrm{r} 1}\left(\varepsilon_{\mathrm{r} 2}\right)$ and $h_{1}\left(h_{2}\right)$, respectively. The antenna substrate selected in this study is a $3.2 \mathrm{~mm}$-thick Taconic TLY-5 substrate $\left(\varepsilon_{\mathrm{r}}=2.2, \tan \delta=0.0009\right)$. The microstrip line has a width of $w_{\mathrm{f}}$ and an open-circuited stub length of $\ell_{s}$, and is designed to have a characteristic impedance of $50 \Omega$.

To investigate the effect of the aperture ratio on the impedance bandwidth of an ACMA according to the coupling strength from a feed line to a patch, two types of

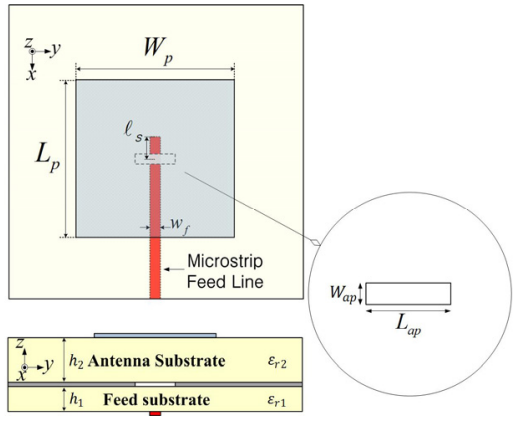

Fig. 1. Geometry of an ACMA.

\begin{tabular}{|c|c|c|c|c|c|c|c|}
\hline $\begin{array}{l}\text { Antenna } \\
\text { Model \# }\end{array}$ & $\varepsilon_{\mathrm{r} 1}$ & $\begin{array}{c}h_{1} \\
{[\mathrm{~mm}]}\end{array}$ & $\begin{array}{l}L_{\mathrm{p}}=W_{\mathrm{p}} \\
{[\mathrm{mm}]}\end{array}$ & $\begin{array}{c}\boldsymbol{L}_{\mathrm{ap}} \\
{[\mathbf{m m}]}\end{array}$ & $\begin{array}{c}W_{\text {ap }} \\
{[\mathrm{mm}]}\end{array}$ & $\begin{array}{c}\ell_{\mathrm{s}} \\
{[\mathrm{mm}]}\end{array}$ & $\begin{array}{c}w_{\mathrm{f}} \\
{[\mathrm{mm}]}\end{array}$ \\
\hline 1 & \multirow{3}{*}{2.2} & 0.25 & \multirow{6}{*}{7.2} & 7.6 & 0.76 & 1.6 & 0.76 \\
\hline 2 & & 0.78 & & 8 & 0.8 & 1.7 & 2.69 \\
\hline 3 & & 1.58 & & 8.4 & 0.84 & 1.9 & 4.7 \\
\hline 4 & \multirow{3}{*}{10} & 0.28 & & 6.2 & 0.62 & 0.7 & 0.27 \\
\hline 5 & & 0.64 & & 5.8 & 0.58 & 0.7 & 0.60 \\
\hline 6 & & 0.78 & & 5.6 & 0.56 & 0.7 & 0.69 \\
\hline
\end{tabular}

Tab. 1. Design parameters of the six ACMAs.

substrates having different dielectric constants were used as the feed substrate. One feed substrate is the Taconic CER-10 substrate $\left(\varepsilon_{\mathrm{r}}=10, \tan \delta=0.0035\right)$ suitable for integration with MMICs. The other feed substrate is the Taconic TLY-5 substrate. The aperture is designed for using a mutual resonance produced by the interaction between the aperture and the patch to obtain a wide impedance bandwidth. The three ACMAs with the low permittivity feed substrate with three different commercially available thicknesses and those with the high permittivity feed substrate with three different commercially available thicknesses are designed to obtain the maximum impedance bandwidth at the center frequency of $10 \mathrm{GHz}$ when the aperture ratio has a typical value of 0.1 . The design parameters of the six ACMAs are shown in Tab. 1.

Figures 2(a) and 2(b) show the simulated return loss of the three ACMAs with the design parameters of $\varepsilon_{\mathrm{r} 1}=2.2$ and $\varepsilon_{\mathrm{r} 1}=10$, respectively, shown in Tab. 1. In Fig. 2(a), the simulated $10 \mathrm{~dB}$ return loss bandwidths of the ACMAs with the low permittivity feed substrate with $h_{1}=0.25 \mathrm{~mm}$, $0.78 \mathrm{~mm}$, and $1.58 \mathrm{~mm}$ are $33.02 \%(8.37-11.68 \mathrm{GHz})$, $36.53 \%(8.28-11.98 \mathrm{GHz})$, and $38.45 \%(8.21-12.12 \mathrm{GHz})$, respectively. In Fig. 2(b), the simulated $10 \mathrm{~dB}$ return loss bandwidths of the ACMAs with the high permittivity feed substrate with $h_{1}=0.28 \mathrm{~mm}, 0.64 \mathrm{~mm}$, and $0.78 \mathrm{~mm}$ are $25.62 \%$ (8.85-11.45 GHz), 21.95\% (8.88-11.07 GHz), and $20.61 \%(9.05-11.13 \mathrm{GHz})$, respectively. It can be seen that the $10 \mathrm{~dB}$ return loss bandwidths of the ACMAs with the high permittivity feed substrate are much smaller than those of the ACMAs with the low permittivity feed substrate.

The parameter $n_{\mathrm{f}}$ representing the coupling strength between the feed line and the aperture of an ACMA is given by (1) [11].

$$
n_{\mathrm{f}}=1-\exp \left(-\frac{L_{\mathrm{ap}}}{4 h_{1}}\right) .
$$




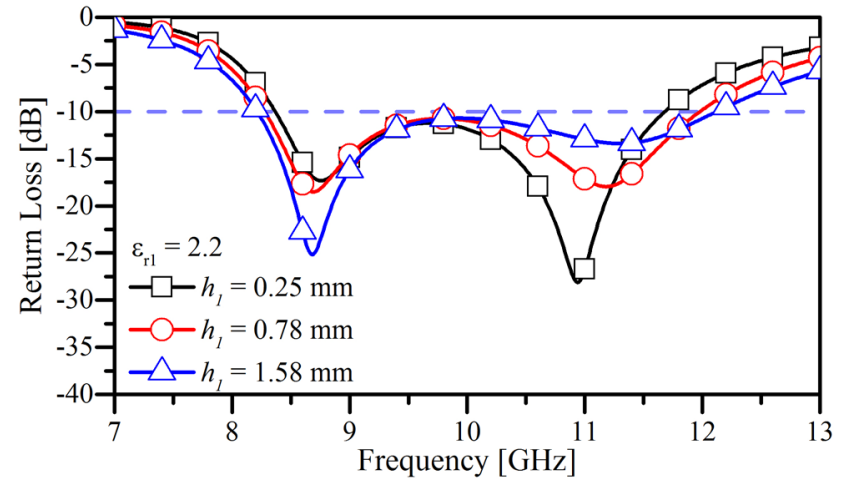

(a)

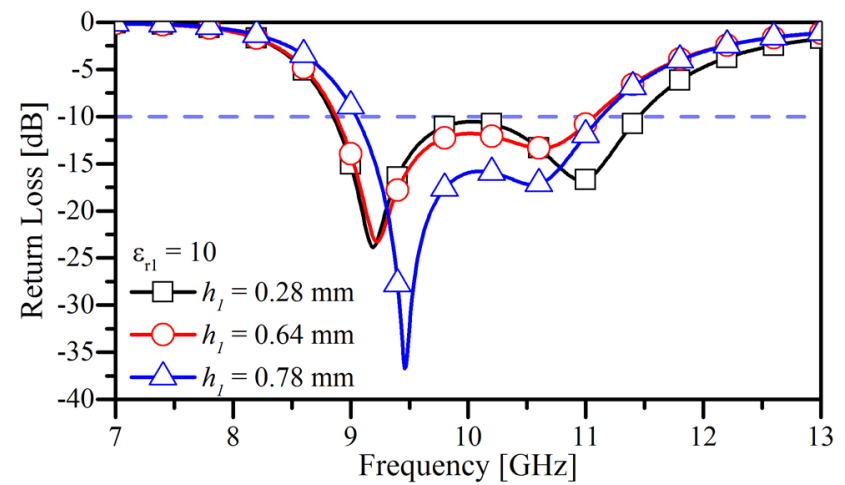

(b)

Fig. 2. Return loss of the six ACMAs with the design parameters shown in Tab. 1. (a) Three ACMAs with the low permittivity feed substrate with three different thicknesses and (b) three ACMAs with the high permittivity feed substrate with three different thicknesses.

\begin{tabular}{|c|c|c|c|c|c|c|c|}
\hline $\begin{array}{l}\text { Antenna } \\
\text { Model \# }\end{array}$ & $\varepsilon_{\mathrm{r} 1}$ & $\begin{array}{c}h_{1} \\
{[\mathrm{~mm}]}\end{array}$ & $\begin{array}{c}L_{\mathrm{p}}=W_{\mathrm{p}} \\
{[\mathrm{mm}]}\end{array}$ & $\begin{array}{c}\boldsymbol{L}_{\text {ap }} \\
{[\mathrm{mm}]}\end{array}$ & $n_{\mathrm{f}}$ & $n_{\mathrm{p}}$ & $n_{\mathrm{f}} \times n_{\mathrm{p}}$ \\
\hline 1 & \multirow{3}{*}{2.2} & 0.25 & \multirow{6}{*}{7.2} & 7.6 & 0.9995 & 0.528 & 0.528 \\
\hline 2 & & 0.78 & & 8 & 0.923 & 0.556 & 0.513 \\
\hline 3 & & 1.58 & & 8.4 & 0.735 & 0.583 & 0.429 \\
\hline 4 & \multirow{3}{*}{10} & 0.28 & & 6.2 & 0.996 & 0.431 & 0.429 \\
\hline 5 & & 0.64 & & 5.8 & 0.896 & 0.403 & 0.361 \\
\hline 6 & & 0.78 & & 5.6 & 0.834 & 0.389 & 0.324 \\
\hline
\end{tabular}

Tab. 2. Coupling strength of the six ACMAs.

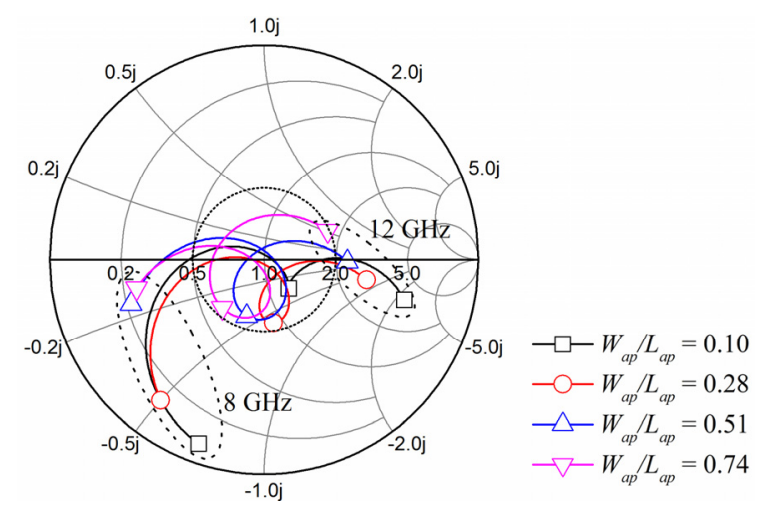

Fig. 3. Input impedance loci plotted on a Smith chart of ACMAs with a $0.78 \mathrm{~mm}$-thick high permittivity $\left(\varepsilon_{\mathrm{r}}=10\right)$ feed substrate for various aperture ratios.

The parameter $n_{\mathrm{p}}$ representing the coupling strength between the aperture and the patch of an ACMA is given by (2) [11].

$$
n_{\mathrm{p}}=\frac{L_{\mathrm{ap}}}{2 W_{\mathrm{p}}} .
$$

Table 2 shows the values of $n_{\mathrm{f}}, n_{\mathrm{p}}$, and $n_{\mathrm{f}} \times n_{\mathrm{p}}$ of the six ACMAs. The parameter $n_{\mathrm{f}} \times n_{\mathrm{p}}$ represents the coupling strength between the feed line and the patch of an ACMA.

Since the aperture length of an ACMA with the high permittivity feed substrate is less than that with the low permittivity feed substrate, the $n_{\mathrm{f}} \times n_{\mathrm{p}}$ of an ACMA with the high permittivity feed substrate is smaller than that with the low permittivity feed substrate. The $n_{\mathrm{f}} \times n_{\mathrm{p}}$ of an ACMA decreases as the feed substrate thickness increases because the parameter $n_{\mathrm{f}}$ representing the coupling strength between the feed line and the aperture decreases. The $n_{\mathrm{f}} \times n_{\mathrm{p}}$ of an ACMA with a $0.28 \mathrm{~mm}$-thick high-permittivity $\left(\varepsilon_{\mathrm{r}}=10\right)$ feed substrate and that with a $1.58 \mathrm{~mm}-$ thick low permittivity $\left(\varepsilon_{\mathrm{r}}=2.2\right)$ feed substrate are both 0.429 .

To investigate the effect of the aperture ratio on the impedance bandwidth of an ACMA according to the coupling strength from a feed line to a patch, studies are carried out of the input impedance loci plotted on a Smith chart of ACMAs with a $0.78 \mathrm{~mm}$-thick high-permittivity $\left(\varepsilon_{\mathrm{r}}=10\right)$ feed substrate and those with a $0.78 \mathrm{~mm}$-thick low-permittivity $\left(\varepsilon_{\mathrm{r}}=2.2\right)$ feed substrate for various aperture ratios.

Figure 3 shows the input impedance loci plotted on a Smith chart of ACMAs with a $0.78 \mathrm{~mm}$-thick high-permittivity $\left(\varepsilon_{\mathrm{r}}=10\right)$ feed substrate for various aperture ratios. The aperture length was fixed at $5.6 \mathrm{~mm}$, as shown in Tab. 1. Thus, the aperture width was varied to obtain various aperture ratios. The stub length was optimized for maximum impedance bandwidth when the aperture width was changed. The inner circle on a Smith chart represents the circle on which the voltage standing wave ratio (VSWR) is 2. The input impedance loci plotted on a Smith chart of ACMAs with the aperture ratios of $0.1,0.28,0.51$, and 0.74 are shown in Fig. 3. It can be seen that the loop size of an impedance locus produced by the interaction of the aperture with the patch inside the inner circle increases as the aperture ratio increases from 0.1 to 0.51 . This means that the $10 \mathrm{~dB}$ return loss bandwidth increases as the aperture ratio increases from 0.1 to 0.51 . However, it can be seen that the loop size of an impedance locus inside the inner circle is almost the same when the aperture ratio increases beyond 0.51 . This means that the $10 \mathrm{~dB}$ return loss bandwidths are almost the same when the aperture ratio increases beyond 0.51 .

Figure 4 shows the input impedance loci plotted on a Smith chart of ACMAs with a 0.78 mm-thick low permittivity $\left(\varepsilon_{\mathrm{r}}=2.2\right)$ feed substrate for various aperture ratios. The aperture length was fixed at $8.0 \mathrm{~mm}$, as shown in Tab. 1. Thus, the aperture width was varied to obtain various aperture ratios. The input impedance loci plotted on a Smith chart of ACMAs with the aperture ratios of 0.04 , $0.1,0.16$, and 0.23 are shown in Fig. 4. It is shown that the loop size of an impedance locus inside the inner circle 


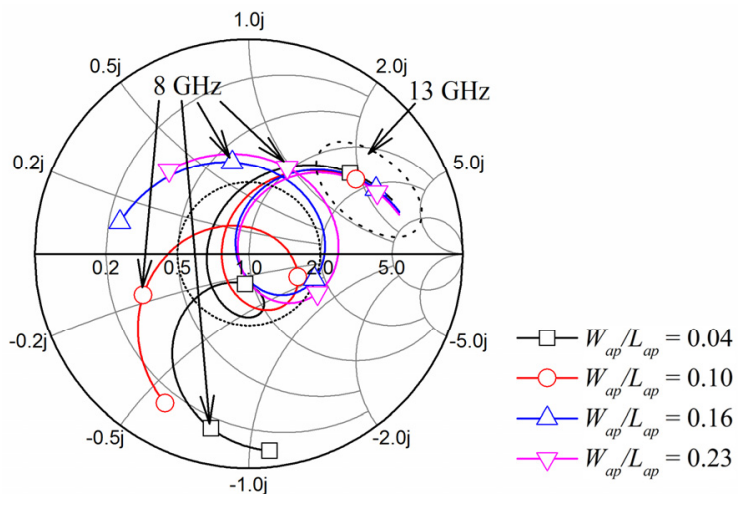

Fig. 4. Input impedance loci plotted on a Smith chart of ACMAs with a $0.78 \mathrm{~mm}$-thick low permittivity $\left(\varepsilon_{\mathrm{r}}=2.2\right)$ feed substrate for various aperture ratios.

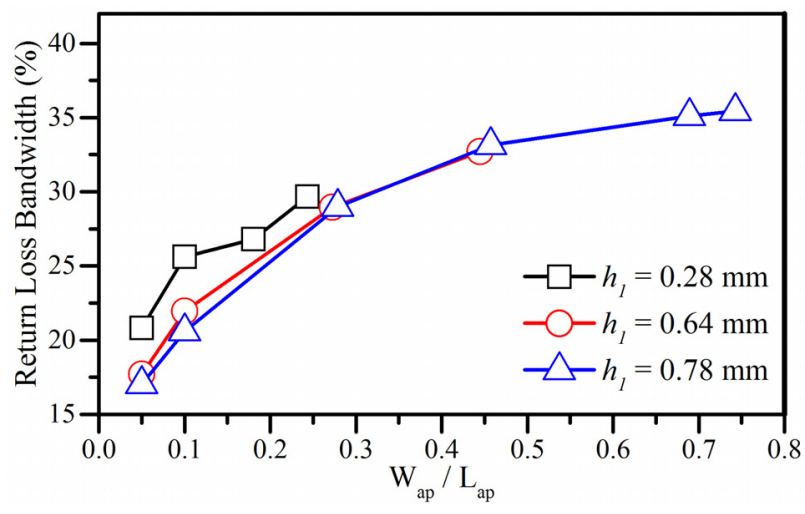

Fig. 5. Simulated $10 \mathrm{~dB}$ return loss bandwidth of ACMAs with the high permittivity feed substrate for various feed substrate thicknesses versus the aperture ratio.

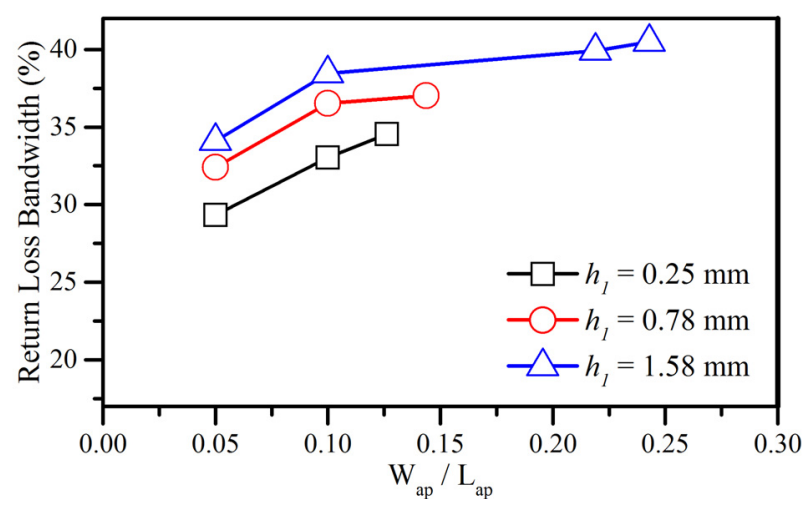

Fig. 6. Simulated $10 \mathrm{~dB}$ return loss bandwidth of ACMAs with the low permittivity feed substrate for various feed substrate thicknesses versus the aperture ratio.

increases as the aperture ratio increases from 0.04 to 0.1 . This means that the $10 \mathrm{~dB}$ return loss bandwidth increases as the aperture ratio increases from 0.04 to 0.1 . It is also shown that the loop size of an impedance locus increases when the aperture ratio increases beyond 0.1. However, part of the loop of an impedance locus exists outside the circle on which the VSWR is 2 for the aperture ratio of 0.16 and 0.23 . This means that the $10 \mathrm{~dB}$ return loss bandwidths of ACMAs with the aperture ratio of 0.16 and 0.23 are smaller than that of the ACMA with the aperture ratio of 0.1 .
Figure 5 shows the simulated $10 \mathrm{~dB}$ return loss bandwidth of ACMAs with the high permittivity feed substrate for various feed substrate thicknesses versus the aperture ratio. Since the antenna $6\left(h_{1}=0.78 \mathrm{~mm}\right)$ has the smallest coupling strength between the feed line and the patch of 0.324 as shown in Tab. 2 , the impedance bandwidth of the antenna 6 increases as the aperture ratio increases beyond 0.1 . The maximum impedance bandwidth of $35.43 \%$ is obtained when the aperture ratio is 0.74 . The impedance bandwidth was increased by about $71.9 \%$ compared with that obtained at the aperture ratio of 0.1 . Antenna 5 $\left(h_{1}=0.64 \mathrm{~mm}\right)$ has the coupling strength between the feed line and the patch of 0.361 . The maximum impedance bandwidth of $32.71 \%$ is obtained when the aperture ratio is 0.44 . The impedance bandwidth was increased by about $49.0 \%$ compared with that obtained at the aperture ratio of 0.1 . Since the antenna $4\left(h_{1}=0.28 \mathrm{~mm}\right)$ has the largest coupling strength between the feed line and the patch of 0.429 , the maximum impedance bandwidth of $29.67 \%$ is obtained when the aperture ratio is 0.24 . The impedance bandwidth was increased by about $15.8 \%$ compared with that obtained at the aperture ratio of 0.1 . It can be seen that, as the feed substrate thickness increases, the coupling strength between the feed line and patch decreases; therefore, the aperture ratio for the maximum impedance bandwidth increases and the normalized maximum impedance bandwidth increases. The normalized maximum impedance bandwidth is defined as the ratio of the maximum impedance bandwidth to the impedance bandwidth obtained at the aperture ratio of 0.1 .

Figure 6 shows the simulated $10 \mathrm{~dB}$ return loss bandwidth of ACMAs with the low permittivity feed substrate for various feed substrate thicknesses versus the aperture ratio. Since the antenna $3\left(h_{1}=1.58 \mathrm{~mm}\right)$ has a coupling strength of 0.429 between the feed line and the patch as shown in Tab. 2, the maximum impedance bandwidth of $40.49 \%$ is obtained when the aperture ratio is 0.24 . The impedance bandwidth was increased by about $5.3 \%$ compared with that obtained at the aperture ratio of 0.1 . Antenna $2\left(h_{1}=0.78 \mathrm{~mm}\right)$ has the coupling strength between the feed line and patch of 0.513 . The maximum impedance bandwidth of $37.03 \%$ is obtained when the aperture ratio is 0.14 . The impedance bandwidth was increased by about $1.4 \%$ compared with that obtained at the aperture ratio of 0.1 . Antenna $1\left(h_{1}=0.25 \mathrm{~mm}\right)$ has the coupling strength of 0.528 between the feed line and the patch. The maximum impedance bandwidth of $34.54 \%$ is obtained when the aperture ratio is 0.13 . The impedance bandwidth was increased by approximately $4.6 \%$ compared with that obtained at the aperture ratio of 0.1 . Since the coupling strength between the feed line and the patch of the three ACMAs with the low permittivity feed substrate used in Fig. 6 is greater than 0.429, the impedance bandwidths of the three ACMAs are almost saturated as the aperture ratio increases beyond 0.1 . The maximum impedance bandwidths of the three ACMAs are approximately the same as the impedance bandwidths obtained at the aperture ratio of 0.1 . 


\section{Simulation and Experiment Results of the Impedance Bandwidth and Radiation Characteristics of ACMAs with a High Permittivity Feed Substrate}

In this section, the impedance bandwidth and radiation characteristics of ACMAs with a 0.78 mm-thick highpermittivity $\left(\varepsilon_{\mathrm{r}}=10\right)$ feed substrate for various aperture ratios are investigated by experiment and simulation.

Figures 7(a), 7(b), and 7(c) show the layouts and photographs of the fabricated ACMAs with the aperture ratios of $0.1,0.51$, and 0.74 , respectively. The dimensions of the fabricated ACMAs shown in Fig. 7 are also shown in Tab. 3 .

Figures 8(a), 8(b), and 8(c) show the simulated and measured return loss of the fabricated ACMAs shown in Fig. 7 with the aperture ratios of $0.1,0.51$, and 0.74 , respectively. The measured results are in good agreement with the simulated results. It can be seen that the measured $10 \mathrm{~dB}$ return loss bandwidth of the ACMA with the aperture ratio of 0.1 is $22.53 \%(8.90-11.16 \mathrm{GHz})$, as shown in Fig. 8(a), while that with the aperture ratio of 0.51 is $34.64 \%(8.21-11.65 \mathrm{GHz})$, as shown in Fig. 8(b). The improvement in the bandwidth is $55.3 \%$ when the aperture ratio is increased from 0.1 to 0.51 . It can be seen that the measured $10 \mathrm{~dB}$ return loss bandwidth of the ACMA with the aperture ratio of 0.74 is $34.98 \%(8.09-11.52 \mathrm{GHz})$, as shown in Fig. 8(c). The bandwidth is almost the same when the aperture ratio is larger than 0.51 .

Figures 9(a), 9(b), and 9(c) show the simulated and measured E-plane radiation patterns of the fabricated ACMAs shown in Fig. 7 with the aperture ratios of 0.1 , 0.51 , and 0.74 , respectively, at $10 \mathrm{GHz}$. In the case of the co-polarization patterns, the measured results are in good agreement with the simulated results. The simulated crosspolarization gains of ACMAs with the aperture ratios of $0.1,0.51$, and 0.74 are less than $-37.56 \mathrm{dBi},-39.77 \mathrm{dBi}$, and $-39.11 \mathrm{dBi}$, respectively. The measured results for the cross-polarization gains of the fabricated ACMAs with

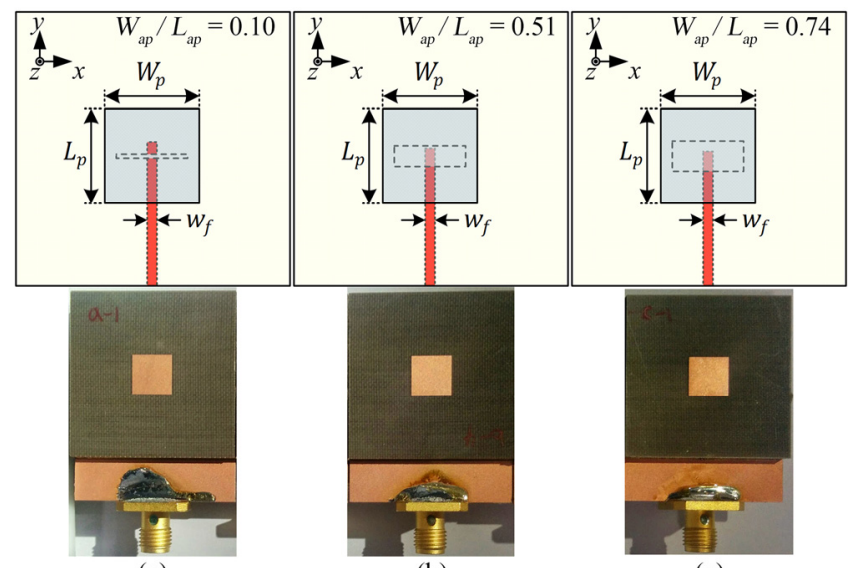

(a)

(b)

(c)

Fig. 7. Layouts and photographs of the fabricated ACMAs with a $0.78 \mathrm{~mm}$-thick high permittivity feed substrate for the three different aperture ratios: (a) $W_{\text {ap }} / L_{\text {ap }}=0.1$, (b) $W_{\text {ap }} / L_{\text {ap }}=0.51$, and (c) $W_{\text {ap }} / L_{\text {ap }}=0.74$.

\begin{tabular}{|c|c|c|c|c|c|}
\hline Fig. 7 & $\begin{array}{c}L_{\mathrm{p}}=W_{\mathrm{p}} \\
{[\mathrm{mm}]}\end{array}$ & $\begin{array}{c}L_{\text {ap }} \\
{[\mathrm{mm}]}\end{array}$ & $\begin{array}{c}W_{\text {ap }} \\
{[\mathrm{mm}]}\end{array}$ & $\begin{array}{c}\ell_{s} \\
{[\mathrm{~mm}]}\end{array}$ & $\begin{array}{c}w_{\mathrm{f}} \\
{[\mathrm{mm}]}\end{array}$ \\
\hline (a) & \multirow{3}{*}{7.2} & \multirow{3}{*}{5.6} & 0.56 & 0.7 & \multirow{3}{*}{0.69} \\
\hline (b) & & & 2.86 & 0.6 & \\
\hline (c) & & & 4.16 & 0.3 & \\
\hline
\end{tabular}

Tab. 3. Dimensions of the fabricated ACMAs shown in Fig. 7.

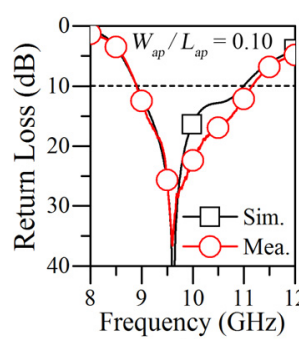

(a)

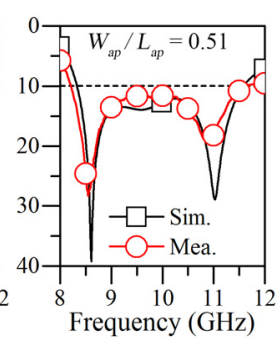

(b)

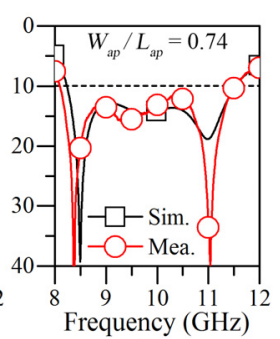

(c)
Fig. 8. Simulated and measured return loss of the fabricated ACMAs shown in Fig. 7 with the three different aperture ratios: (a) $W_{\text {ap }} / L_{\text {ap }}=0.1$, (b) $W_{\text {ap }} / L_{\text {ap }}=0.51$, and (c) $W_{\text {ap }} / L_{\text {ap }}=0.74$.

three different aperture ratios show larger values than the simulated results due to the alignment error of the antenna with respect to the probe in the measurement process.

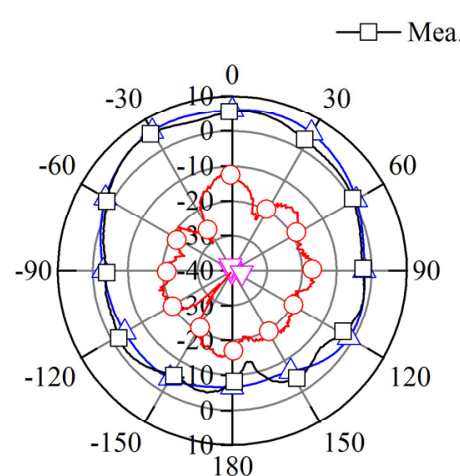

(a)

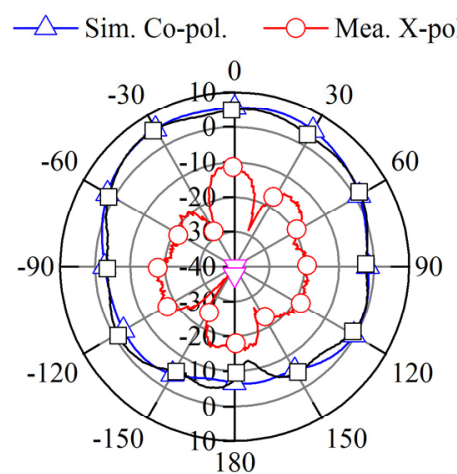

(b)

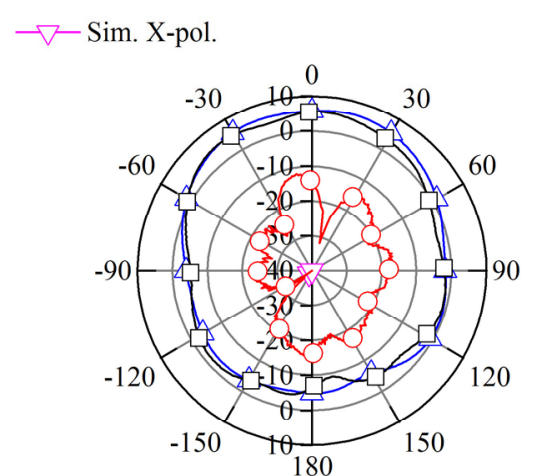

(c)

Fig. 9. Simulated and measured E-plane radiation patterns of the fabricated ACMAs shown in Fig. 7 with the three different aperture ratios at $10 \mathrm{GHz}$ : (a) $W_{\text {ap }} / L_{\text {ap }}=0.1$, (b) $W_{\text {ap }} / L_{\text {ap }}=0.51$, and (c) $W_{\text {ap }} / L_{\text {ap }}=0.74$. 


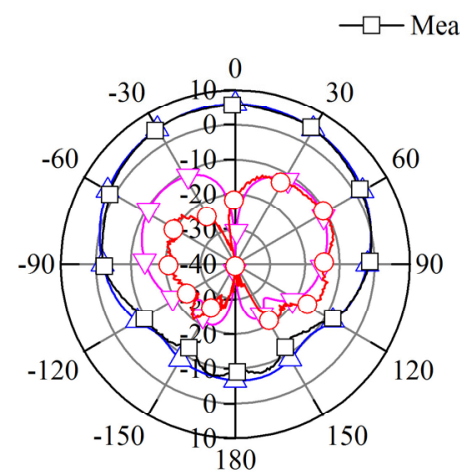

(a)

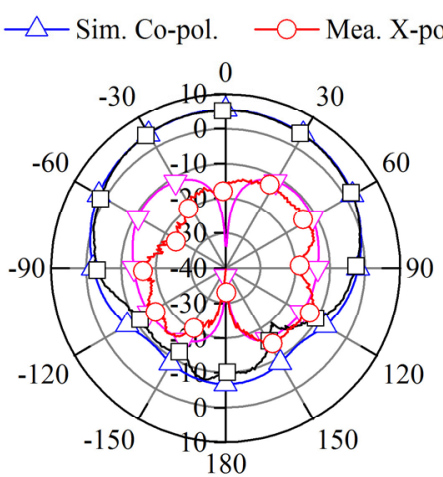

(b)

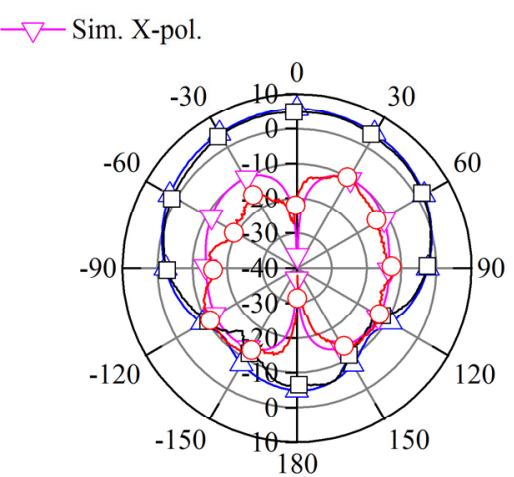

(c)

Fig. 10. Simulated and measured H-plane radiation patterns of the fabricated ACMAs shown in Fig. 7 with the three different aperture ratios at $10 \mathrm{GHz}:$ (a) $W_{\text {ap }} / L_{\text {ap }}=0.1$, (b) $W_{\text {ap }} / L_{\text {ap }}=0.51$, and (c) $W_{\text {ap }} / L_{\text {ap }}=0.74$.

The measured (simulated) broadside gains of the ACMAs with the aperture ratios of $0.1,0.51$, and 0.74 are $5.46 \mathrm{dBi}(5.94 \mathrm{dBi}), 5.11 \mathrm{dBi}(5.41 \mathrm{dBi})$, and $5.39 \mathrm{dBi}$ (5.69 dBi), respectively. The measured (simulated) frontto-back ratios (FBRs) of the ACMAs with the aperture ratios of $0.1,0.51$, and 0.74 are $9.48 \mathrm{~dB}(10.33 \mathrm{~dB})$, $9.74 \mathrm{~dB}(9.87 \mathrm{~dB})$, and $9.37 \mathrm{~dB}(9.54 \mathrm{~dB})$, respectively. The FBR in this work is defined as the ratio of the broadside gain to the maximum value of all back lobes within the cone of $\pm 30^{\circ}$ around the negative $\mathrm{z}$ axis with respect to the forward radiation [13]. The measured (simulated) cross-polarization levels of the ACMAs with the aperture ratios of $0.1,0.51$, and 0.74 are $-17.41 \mathrm{~dB}(-43.5 \mathrm{~dB})$, $-16.17 \mathrm{~dB} \quad(-45.18 \mathrm{~dB})$, and $-17.41 \mathrm{~dB} \quad(-44.8 \mathrm{~dB})$, respectively. Since the simulated cross-polarization gains of the ACMAs are significantly smaller than the measured cross-polarization gains, the simulated cross-polarization levels of the ACMAs are much smaller than the measured cross-polarization levels. The cross-polarization level in this work is defined as the maximum cross-polarization in the broadside relative to the maximum co-polarized field [14].

Figures 10(a), 10(b), and 10(c) show the simulated and measured H-plane radiation patterns of the fabricated ACMAs shown in Fig. 7 with the aperture ratios of 0.1 , 0.51 , and 0.74 , respectively, at $10 \mathrm{GHz}$. In the case of the co-polarization patterns, the measured results are in good agreement with the simulated results. The measured (simulated) cross-polarization gains of ACMAs with the aperture ratios of $0.1,0.51$, and 0.74 are less than $-10.28 \mathrm{dBi}$ $(-10.34 \mathrm{dBi}),-12.68 \mathrm{dBi}(-10.56 \mathrm{dBi})$, and $-10.09 \mathrm{dBi}$ $(-10.13 \mathrm{dBi})$, respectively. The measured cross-polarization gains are slightly different from the simulated crosspolarization gains.

The measured (simulated) FBRs of the ACMAs with the aperture ratios of $0.1,0.51$, and 0.74 are $12.84 \mathrm{~dB}$ (12.54 dB), $12.74 \mathrm{~dB}(12.2 \mathrm{~dB})$, and $11.1 \mathrm{~dB}(10.64 \mathrm{~dB})$, respectively. The measured (simulated) cross-polarization levels of the ACMAs with the aperture ratios of $0.1,0.51$, and 0.74 are $\quad-15.74 \mathrm{~dB} \quad(-16.28 \mathrm{~dB}), \quad-17.79 \mathrm{~dB}$ $(-15.97 \mathrm{~dB})$, and $-15.48 \mathrm{~dB}(-15.82 \mathrm{~dB})$, respectively.
It is found that the ACMAs with the aperture ratios of $0.1,0.51$, and 0.74 have similar radiation patterns. The ACMAs with the high permittivity feed substrate with the aperture ratios of $0.1,0.51$, and 0.74 have similar values to those of the broadside gain, FBR, and cross-polarization level. It can be seen that the variation of the radiation characteristics of the ACMA with the high permittivity feed substrate is very small due to the variation of the aperture ratio.

The radiation patterns of the ACMAs with the aperture ratios of $0.1,0.51$, and 0.74 were measured across the $10 \mathrm{~dB}$ return loss bandwidth and the results were similar to those shown in Figs. 9 and 10.

\section{Conclusion}

The effect of the aperture ratio on the impedance bandwidth of an ACMA is investigated according to the coupling strength from a feed line to a patch of an ACMA. Due to the large coupling strength between the feed line and the patch of the three ACMAs with a low-permittivity $\left(\varepsilon_{\mathrm{r}}=2.2\right)$ feed substrate with three different thicknesses, the impedance bandwidths of the three ACMAs are almost saturated as the aperture ratio increases beyond 0.1 . Thus, the maximum impedance bandwidths of the three ACMAs are approximately the same as the impedance bandwidths obtained at the aperture ratio of 0.1 .

On the other hand, due to the small coupling strength between the feed line and the patch of the three ACMAs with a high-permittivity $\left(\varepsilon_{\mathrm{r}}=10\right)$ feed substrate with three different thicknesses, the impedance bandwidths of the three ACMAs increase as the aperture ratio increases beyond 0.1. As the feed substrate thickness increases, the coupling strength between the feed line and the patch decreases. Thus, the aperture ratio for the maximum impedance bandwidth increases and the normalized maximum impedance bandwidth increases.

The results show that the effect of altering the aperture ratio on the radiation characteristics of ACMAs with a high-permittivity $\left(\varepsilon_{\mathrm{r}}=10\right)$ feed substrate is small. The im- 
pedance bandwidth of an ACMA with a high permittivity $\left(\varepsilon_{\mathrm{r}}=10\right)$ feed substrate suitable for integration with MMICs can be greatly increased with a small degradation of the radiation characteristics of the ACMA by increasing the aperture ratio beyond 0.1 .

\section{Acknowledgments}

This research was supported by the Basic Science Research Program through the National Research Foundation (NRF) of Korea funded by the Ministry of Education (2015R1D1A1A01059745).

\section{References}

[1] CHEN, Z. N., LUK, K. M. Antennas for Base Stations in Wireless Communications. $1^{\text {st }}$ ed., NewYork: McGraw-Hill, 2009. ISBN: 0387723994

[2] GRAG, R., BHARTIA, P., BAHL, I., ITTIPIBOON, A. Microstrip Antenna Design Handbook. $2^{\text {nd }}$ ed., Boston, London: Artech House, 2000. ISBN: 0890065136

[3] WATERHOUSE, R. B. Microstrip Patch Antennas: A Designer's Guide. Boston(MA): Kluwer Academic, 2003. ISBN: 1441953388

[4] WONG, K.-L. Compact and Broadband Microstrip Antennas. $1^{\text {st }}$ ed., New York: John Wiley \& Sons, 2002. ISBN: 0471417173

[5] TARgOnSKi, S. D., WATERhOUSE, R. B., POZAR, D. M. Design of wide-band aperture-stacked patch microstrip antennas. IEEE Transactions on Antennas and Propagation, 1998, vol. 46 , no. 9, p. 1245-1251. DOI: 10.1109/8.719966

[6] PAVuluri, S. K., WANG, C., SANGSTER, A. J. High efficiency wideband aperture-coupled stacked patch antennas assembled using millimeter thick micromachined polymer structure. IEEE Transactions on Antennas and Propagation, 2010, vol. 58, no. 11, p. 3616-3621. DOI: 10.1109/TAP.2010.2071334

[7] BARBA, M. A high-isolation, wideband and dual-linear polarization patch antenna. IEEE Transactions on Antennas and Propagation, 2008, vol. 56, no. 3, p. 1472-1476. DOI: 10.1109/TAP.2008.922889

[8] ROWE, W. S. T., WATERHOUSE, R. B. Theoretical investigation on the use of high permittivity materials in microstrip aperture stacked patch antennas. IEEE Transactions on Antennas and Propagation, 2003, vol. 51, no. 9, p. 2484-2486. DOI: 10.1109/TAP.2003.816383

[9] SUlLIVAN, P. L., SCHAUBERT, D. H. Analysis of an aperture coupled microstrip antenna. IEEE Transactions on Antennas and
Propagation, 1986, vol. 34, no. 8, p. 977-984. DOI: 10.1109/TAP.1986.1143929

[10] POZAR, D. M. A Review of Aperture Coupled Microstrip Antennas: History, Operation, Development, and Applications. 12 p. [Online] Cited 2017-12-08. Available at: http: //www.ecs.umass.edu/ece/pozar/aperture.pdf

[11] LIU, L., KOROLKIEWICZ, E., GHASSEMLOOY, Z., SAMBELL, A., DANAHER, S., BUSAWON, K. Investigation of the equivalent circuit parameters and design of a dual polarised dual frequency aperture coupled microstrip antenna. IEEE Transactions on Antennas and Propagation, 2013, vol. 61, no. 4, p. 2304-2308. DOI: 10.1109/TAP.2013.2241716

[12] LAI, A., LEONG, K. M. K. H., ITOH, T. Infinite wavelength resonant antennas with monopolar radiation pattern based on periodic structures. IEEE Transactions on Antennas and Propagation, 2007, vol. 55, no. 3, p. 868-876. DOI: 10.1109/TAP.2007.891845

[13] GUO, Y.-X., LUK, K.-M., LEE, K.-F. L-probe fed thick-substrate patch antenna mounted on a finite ground plane. IEEE Transactions on Antennas and Propagation, 2003, vol. 51, no. 8, p. 1955-1963. DOI: 10.1109/TSP.2003.815430

[14] BHARDWAJ, S., RAHMAT-SAMII, Y. Revisiting the generation of cross-polarization in rectangular patch antennas: A near-field approach. IEEE Transactions on Antennas and Propagation, 2014, vol. 56, no. 1, p. 14-38. DOI: 10.1109/MAP.2014.6821758

\section{About the Authors ...}

Jae-Hyun KIM was born in Seoul, Korea. He received the B.S. and M.S. degrees in Electronic Engineering from the Soongsil University, Seoul, Korea, in 2012 and 2014, respectively. Currently, he is pursuing the Ph.D. degree. His main research interests are in the areas of patch antennas, phased array antennas, and metamaterial.

Boo-Gyoun KIM (corresponding author) was born in Daejon, Korea. He received the B.S. degree in Electronic Engineering from the Seoul National University, Seoul, Korea, in 1979, the M.S. degree in Electronic Engineering from the Korea Advanced Institute of Science and Technology, Seoul, Korea, in 1981, and the Ph.D. degree in Electrical Engineering from the University of Southern California, Los Angeles, USA, in 1989. He joined the School of Electronic Engineering, the Soongsil University, Seoul, in 1981, where he is now a Professor. He was the dean of College of Information Technology of the Soongsil University from March 2008 to February 2010. His main research interests are in the areas of patch antennas, electromagnetic bandgap structures, and phased array antennas. 